\title{
Communication
}

\section{Stereochemistry of Sagittamide A from Residual Dipolar Coupling Enhanced NMR}

Anne Schuetz, Jochen Junker, Andrei Leonov, Oliver F. Lange, Tadeusz F. Molinski, and Christian Griesinger J. Am. Chem. Soc., 2007, 129 (49), 15114-15115• DOI: 10.1021/ja075876l • Publication Date (Web): 14 November 2007

Downloaded from http://pubs.acs.org on March 23, 2009

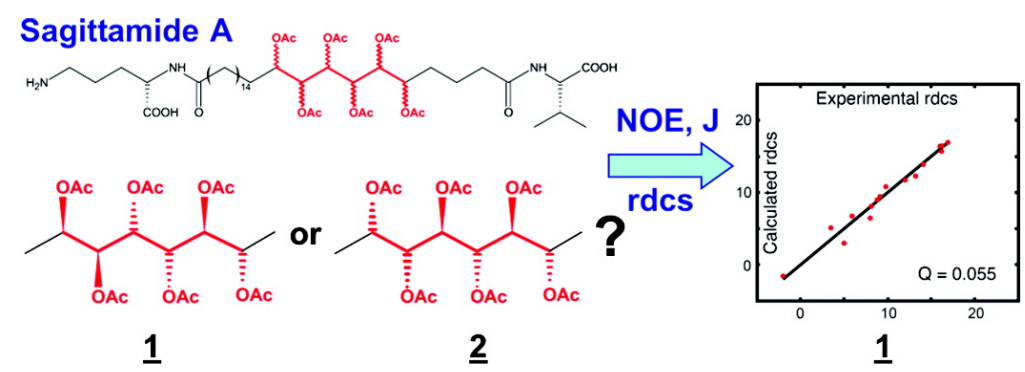

\section{More About This Article}

Additional resources and features associated with this article are available within the HTML version:

- Supporting Information

- Access to high resolution figures

- $\quad$ Links to articles and content related to this article

- $\quad$ Copyright permission to reproduce figures and/or text from this article

\section{View the Full Text HTML}

\section{ACS Publications}




\title{
Stereochemistry of Sagittamide A from Residual Dipolar Coupling Enhanced NMR
}

\author{
Anne Schuetz, ${ }^{\dagger}$ Jochen Junker ${ }^{\dagger}$ Andrei Leonov, ${ }^{\dagger}$ Oliver F. Lange, ${ }^{\S}$ Tadeusz F. Molinski, ${ }^{\ddagger}$ and \\ Christian Griesinger ${ }^{\star} \dagger$ \\ Department of NMR Based Structural Biology, Max Planck Institute for Biophysical Chemistry, Am Fassberg 11, \\ 37077 Göttingen, Germany, Department of Biochemistry, University of Washington, J Wing, Health Sciences \\ Building, Box 357350, Seattle, Washington 98195, and Department of Chemistry and Biochemistry and Skaggs \\ School of Pharmacy and Pharmaceutical Sciences, University of California, San Diego, 9500 Gilman Drive,
} La Jolla, California 92093

Received August 6, 2007; E-mail: cigr@nmr.mpibpc.mpg.de

Sagittamide A (Figure 1a) is a long-chain acyclic $\alpha, \omega$-dicarboxylic acid (C26) that has been isolated from a tropical tunicate. ${ }^{1}$ It contains eight stereocenters, six of which are located in a peracetylated 1,2,3,4,5,6-hexahydroxyhexane unit (C5-C10). The determination of the relative stereochemistry in this unit poses a big challenge for current NMR methods. ${ }^{2}$ For this unit, two different configurations have been proposed: one ${ }^{3}$ shown in Figure $1 \mathrm{~b}$ based on $J$-couplings, ${ }^{4}$ NOEs, and Kishi's universal database of ${ }^{13} \mathrm{C}$ chemical shifts; ${ }^{5}$ the other one ${ }^{6}$ (Figure 1a) using ${ }^{3} J_{\mathrm{HH}}$ spin-coupling constant profiles, ${ }^{7}$ total synthesis of two stereoisomers of Sagittamide $\mathrm{A}$, and comparison of the $1 \mathrm{D}$ proton spectrum in the acetate region with the natural compound.

In the following it will be shown that the stereochemistry of the six stereocenters cannot be determined from $\mathrm{H}, \mathrm{H}$ and $\mathrm{H}, \mathrm{C} J$ couplings and NOEs alone. However, if complemented with $\mathrm{H}, \mathrm{C}$ residual dipolar couplings (RDCs) measured in two alignment media, an unambiguous result will be obtained despite severe overlap in the ${ }^{1} \mathrm{H}$ spectra and conformational heterogeneity. RDCs reflect orientations of bond vectors in molecules ${ }^{8}$ and have only recently become accessible for natural compounds through the availability of alignment media that are compatible with organic solvents such as DMSO. ${ }^{9}$

The $J$-coupling analysis was carried out for all six bonds from $\mathrm{C} 4$ to $\mathrm{C} 10$. The measured coupling constants are listed in the Supporting Information. The $\mathrm{C} 10-\mathrm{C} 11$ bond could not be included because the diastereotopic methylene protons at $\mathrm{C} 11$ were overlapped. ${ }^{3} J_{\mathrm{HH}},{ }^{2} J_{\mathrm{CH}}$, and ${ }^{3} J_{\mathrm{CH}}$ coupling constants were measured including the signs of the latter two from a HECADE experiment. ${ }^{10}$ ${ }^{3} J_{\mathrm{H}, \mathrm{H}}$ coupling constants were taken directly from suitably apodized one-dimensional ${ }^{1} \mathrm{H}$ spectra. All $J$-couplings were translated into dihedral angles according to ref 4 which led to the Newman projections given in Figure 2.

For the three bonds $\mathrm{C} 4-\mathrm{C} 5, \mathrm{C} 7-\mathrm{C} 8$, and $\mathrm{C} 9-\mathrm{C} 10$, the conformation and relative configurations of adjacent stereocenters could be determined unequivocally. The conformation found for the $\mathrm{C} 7-\mathrm{C} 8$ bond is incompatible with the configuration proposed in ref 3 based on the coupling constants: $\mathrm{H} 7, \mathrm{H} 8{ }^{3} J_{\mathrm{HH}}(1.5 \mathrm{~Hz})$; $\mathrm{C} 7, \mathrm{H} 8{ }^{2} J_{\mathrm{CH}}(2.8 \mathrm{~Hz}) ; \mathrm{C} 8, \mathrm{H} 7{ }^{2} J_{\mathrm{CH}}(0.2 \mathrm{~Hz})$; C6,H8 ${ }^{3} J_{\mathrm{CH}}(1.0 \mathrm{~Hz})$; C9, $\mathrm{H} 7{ }^{3} J_{\mathrm{CH}}(0.7 \mathrm{~Hz})$.

For the $\mathrm{C} 5-\mathrm{C} 6$ bond, the $J$-coupling information could only be explained based on the existence of two staggered conformations. Here, the $\mathrm{H} 5, \mathrm{H} 6{ }^{3} J_{\mathrm{HH}}$ coupling $(4.8 \mathrm{~Hz})$ is clearly averaged between trans and gauche with a ratio of approximately $2: 3$, whereas the $\mathrm{H} 5, \mathrm{C} 7{ }^{3} J_{\mathrm{HC}}(1.7 \mathrm{~Hz})$ coupling is pure gauche conformation. The $\mathrm{H} 6, \mathrm{C} 5(-4.1 \mathrm{~Hz})$ and $\mathrm{H} 5, \mathrm{C} 6(-3.7 \mathrm{~Hz})^{2} J_{\mathrm{H}, \mathrm{C}}$ couplings are slightly different, favoring the assignment $\mathrm{A}$ for these two stereocenters in

\footnotetext{
$\dagger$ Max Planck Institute for Biophysical Chemistry.

$\S$ University of Washington.

¥ University of California, San Diego.
}

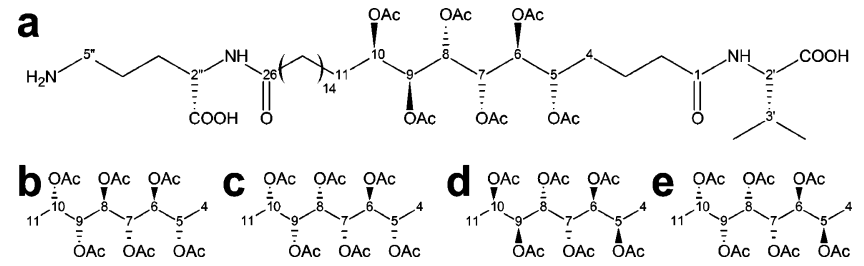

Figure 1. Sagittamide $A$ with $(\mathrm{a})$ the $(A, C)$ configuration as published in ref 6 . $(A, C)$ refers to the Newman projections in Figure 2. (b) The configuration according to ref 3 is shown. The three additionally possible stereoisomers according to the $J$-coupling analysis: (c) epi-9,10 (A,C), (d) epi-5 $(\mathrm{B}, \mathrm{C})$, and (e) epi-5,9,10 (B,D) referring to the stereochemistry of (a) are shown.
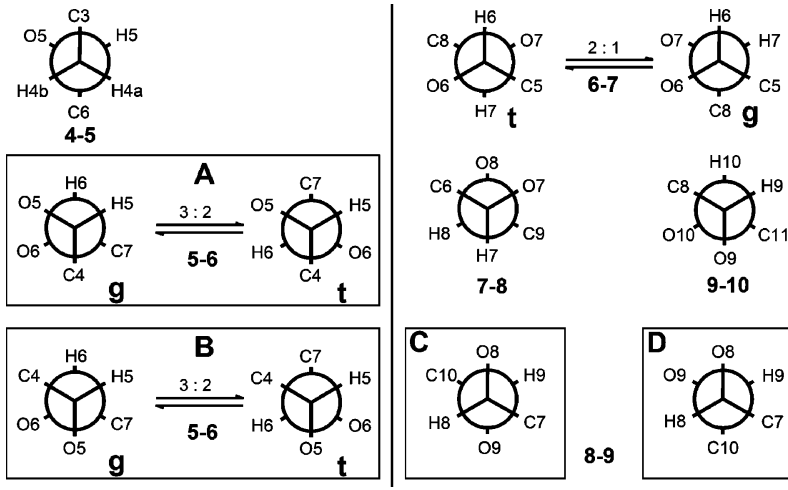

Figure 2. Newman projections for $\mathrm{C} 4-\mathrm{C} 10$ of the $1,2,3,4,5,6$-hexahydroxyhexane moiety of Sagittamide A as derived from $J$-coupling analysis. The relative stereochemistry of C5 versus C6 $(A, B)$ and C8 versus C9 (C,D) cannot be determined unequivocally from $J$-couplings, leaving four relative configurations at this stage. They are also shown in Figure 1.

which the H5,C6 ${ }^{2} J_{\mathrm{H}, \mathrm{C}}$ coupling would be averaged. This difference is not sufficient to safely exclude assignment B in Figure 2. A similar $J$-coupling analysis yields an unambiguous assignment of the relative configuration of the $\mathrm{C} 6-\mathrm{C} 7$ bond and also requires averaging with a ratio of trans/gauche $=2: 1$.

For the remaining $\mathrm{C} 8-\mathrm{C} 9$ bond, all measured $J$-couplings correspond to values expected for pure conformations, indicating no conformational heterogeneity. Since the two protons are antiperiplanar, the distinction between the two different Newman projections $\mathrm{C}$ and D in Figure 2 is not possible, even if all ${ }^{3} J_{\mathrm{HH}}$ and ${ }^{2,3} J_{\mathrm{CH}}$ could be measured. Only the ${ }^{3} J_{\mathrm{C}, \mathrm{C}}$ coupling constant could distinguish between the two relative configurations of C8 and C9. However, this coupling could not be measured due to limitations in the quantity of material. Thus, out of the 32 relative configurations, only four are possible: (A,C) from ref 6; epi-9,10 (A,D); epi-5 (B,C); epi-5,9,10 (B,D). (A/B,C/D) refers to the alternative Newman projections shown in Figure 2. 


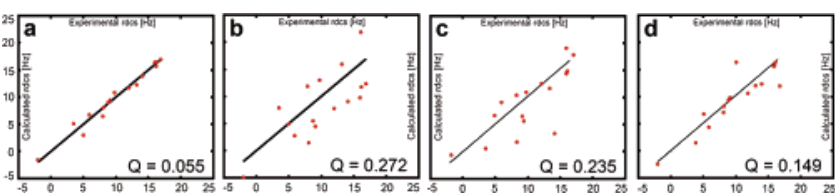

Figure 3. Experimental and back-calculated RDCs for Sagittamide A with configuration according to (a) ref 6, (b) epi-9,10, (c) epi-5, and (d) epi$5,9,10$.

Conformational averaging around the $\mathrm{C} 5-\mathrm{C} 6$ and $\mathrm{C} 6-\mathrm{C} 7$ bonds results in a maximum of four conformations. This requires three variables to describe the populations as the sum is one. The populations were calculated based on the sizes of the H5,H6 and H6, H7 ${ }^{3} J_{\mathrm{HH}}$ coupling constants giving two restraints for the populations. The third was derived from the strong $\mathrm{H} 5, \mathrm{H} 8 \mathrm{NOE}^{11}$ which depends on the three torsion angles $\mathrm{C} 5-\mathrm{C} 6, \mathrm{C} 6-\mathrm{C} 7$, and C7-C8. Since C7-C8 was found to be fixed, it depends only on the populations of the $\mathrm{C} 5-\mathrm{C} 6$ and $\mathrm{C} 6-\mathrm{C} 7$ rotamers. In order to fulfill the distance of $2.5 \pm 0.2 \AA$, the $\mathbf{t g}$ conformation ( $\mathbf{t}$ and $\mathbf{g}$ refer to the $\mathrm{C} 5-\mathrm{C} 6$ and $\mathrm{C} 6-\mathrm{C} 7$ rotamers, respectively, shown in Figure 2) with the distance of $2.5 \AA$ was weighted with the maximum allowed population of $33 \%$, the gt with $60 \%$, the tt with $7 \%$, and the gg conformation with $0 \% .{ }^{12}$ For all four configurations described in Figures 1 and 2, one ensemble of those three conformations with the indicated populations $p_{j}(j=1-3)$ was then generated in XPLOR-NIH ${ }^{13}$ by fixing the dihedral angles. The three conformations with $\mathrm{CH}$ vector orientations $e_{j}\left(j=1-3\right.$; the $e_{j}$ represent unit vectors) were then superimposed in the hexahydroxyhexane moiety.

Conventional $J$-coupling analysis identified ensembles of three conformations for four different configurations. Since a distinction between these four configurations was not achieved based on isotropic parameters, this was therefore left for the RDC-based analysis that is described in the following.

Sagittamide A was aligned in two different media (see Supporting Information). ${ }^{9}$ RDCs $D\left(C_{i} H_{i}\right)^{\text {exp }}$ were obtained from $t_{2}$-coupled ${ }^{1} \mathrm{H},{ }^{13} \mathrm{C}$ HSQC spectra by superimposing and fitting $\omega_{2}$ traces from isotropic and anisotropic spectra according to the procedure described in ref $9 \mathrm{~b}$. The error on the dipolar couplings was estimated to be $0.5 \mathrm{~Hz}$. Two sets of $D\left(C_{i} H_{i}\right)^{\exp }$ for the eight internuclear ${ }^{1} \mathrm{CH}$ vectors from $\mathrm{C} 4$ to $\mathrm{C} 10$ were fitted via a singular value decomposition to reproduce the back-calculated RDCs according to

$$
D\left(C_{i} H_{i}\right)=\sum_{j=1}^{3} p_{j} \overline{e\left(C_{i} H_{i}\right)_{j}^{T}} \hat{A} \overline{e\left(C_{i} H_{i}\right)_{j}}
$$

The previously described ensemble of conformations for the four configurations and one alignment tensor $\hat{A}$ for all three conformations was used.

The $(\mathrm{A}, \mathrm{C})$ stereochemistry (Figure 1a) yielded an excellent fit as shown in Figure $3 \mathrm{a}$ with $Q=0.055 .{ }^{14}$ The axial components $A_{z z}$ of the tensor were 28.3 and $37.9 \mathrm{~Hz}$ for the two media. Given the average values for the order parameter in the ensemble of $S=$ 0.47 with an $A_{z z}$ value of $28.3 / 37.9 \mathrm{~Hz}$, maximum dipolar couplings of the order of $S A_{z z}$ are expected. This is the case for the (A,C) configuration. The order parameter is calculated from the ensemble by superimposing the carbon atoms $\mathrm{C} 4-\mathrm{C} 10$. The other three configurations yielded a significantly larger $Q$ factor and also some unreasonably large $A_{z z}$ components with $Q=0.272$ and $A_{z z}$ values of 57.4 and $82.3 \mathrm{~Hz}$ for epi-9,10, $Q=0.235$ with $A_{z z}=38.2$ and $40.7 \mathrm{~Hz}$ for epi-5, and $Q=0.149$ with an $A_{z z}=46.3$ and $59.2 \mathrm{~Hz}$ for epi-5,9,10. Thus, all but the $(A, C)$ configuration of Figure $1 a^{6}$ can be rejected using RDCs.

We have described here the determination of the relative configuration of an acyclic compound based on a careful conformational analysis using isotropic parameters. The correct configuration was selected using cross validation with RDCs. This approach has worked on the example of Sagittamide A remarkably well despite conformational averaging. In other examples where less $J$-couplings can be measured, the RDC cross validation may not isolate a single configuration but will narrow down the number of possibilities such that synthetic chemists will have fewer target molecules to synthesize.

We have assessed whether the back-calculated alignment tensor $\hat{A}$ is reasonable by multiplication of its axial component $A_{z z}$ with the average order parameter $S$ of the $\mathrm{CH}$ vectors and requiring that $S A_{z z}$ is of the order of the maximum experimental dipolar coupling. This is a strict criterion if $S$ is constant for all $\mathrm{CH}$ vectors and the $\mathrm{CH}$ vectors sample sufficient orientations on the sphere, which also means that at least one average orientation is along the $z$-axis of the $\hat{A}$ tensor. For the hexahydroxyhexane moiety of Sagittamide A, this criterion was remarkably well fulfilled. In contrast, we have found unreasonably large values for $S A_{z z}$ for the rejected stereochemistries.

The assumption of a uniform alignment tensor for different conformations may also not be correct in all cases. For Sagittamide A, this appears to be justified because of the excellent fit of one of the configurations and because the hexahydroxyhexane moiety is only a small part of the whole molecule and the major contribution to alignment is induced by the rest of the molecule. Like for proteins, we do not have indications that the alignment media used change the conformations of Sagittamide A.

In conclusion, for the example of Sagittamide A, we could not only decide between the proposed stereochemistries of refs 3 and 6 but also establish an approach that is robust against conformational averaging. We believe that, with the described methodology, the stereochemistry of a wide range of acyclic natural compounds can be determined and stereoselective synthesis such as published recently for Blasticidine $\mathrm{A}^{2}$ as well as for Sagittamide $\mathrm{A}^{6}$ can be avoided.

Acknowledgment. This work was supported by the Max Planck Society, the Fonds der Chemischen Industrie, and the DFG-GRK 782 (C.G.). Burkhard Luy kindly provided PAN gels. We are grateful for intense discussions with Bert de Groot and Markus Zweckstetter, MPIbpc, Göttingen.

Note added in proof. In light of ref 15, RDCs may also prove to be a sensitive NMR parameter to detect differences in configurations of synthetic and natural products with very similar chemical shifts.

Supporting Information Available: $J$-couplings, RDCs (measured and back-calculated), characteristics of alignment media, and a figure of the correct conformational ensemble. This material is available free of charge via the Internet at http://pubs.acs.org.

\section{References}

(1) Lievens, S. C.; Molinski, T. F. Org. Lett. 2005, 7 (11), 2281-2284.

(2) Sakuda, S.; Matsumori, N.; Furihataa, K.; Nagasawaa, H. Tetrahedron Lett. 2007, 48 (14), 2527-2531.

(3) Lievens, S. C.; Molinski, T. F. J. Am. Chem. Soc. 2006, 128 (36), 1176411765 .

(4) Matsumori, N.; Kaneno, D.; Murata, M.; Nakamura, H.; Tachibana, K. J. Org. Chem. 1999, 64 (3), 866-876.

(5) Higashibayashi, S.; Czechtizky, W.; Kobayashi, Y.; Kishi, Y. J. Am. Chem. Soc. 2003, 125 (47), 14379-14393.

(6) Seike, H.; Ghosh, I.; Kishi, Y. Org. Lett. 2006, 8 (17), 3865-3868.

(7) Seike, H.; Ghosh, I.; Kishi, Y. Org. Lett. 2006, 8 (17), 3861-3864.

(8) Tjandra, N.; Bax, A Science 1997, 278 (5340), 1111-1114.

(9) (a) Freudenberger, J. C.; Knör, S.; Kobzar, K.; Heckmann, D.; Paulutat, T.; Kessler, H.; Luy, B. Angew. Chem., Int. Ed. 2005, 44 (3) 423-426. (b) Haberz, P.; Farjon, J.; Griesinger, C. Angew. Chem., Int. Ed. 2005, 44 (3) 427-429. (c) Kummerloewe, G.; Auernheimer, J.; Lendlein, A.; Luy, B. J. Am. Chem. Soc. 2007, 129 (19), 6080-6081.

(10) Kozminski, W.; Nanz, D. J. Magn. Reson. 1997, 124 (2), 383-392.

(11) Thrippleton, M. J.; Keeler, J. Angew. Chem., Int. Ed. 2003, 42 (33), 39383941.

(12) A detailed derivation of conformer populations is given in the Supporting Information.

(13) (a) Schwieters, C. D.; Kuszewski, J. J.; Tjandra, N.; Clore, G. M. J. Magn. Reson. 2003, 160 (1), 66-74. (b) Schwieters, C. D.; Kuszewski, J. J.; Clore, G. M. Prog. NMR Spectrosc. 2006, 48 (1), 47-62.

(14) Cornilescu, G.; Marquardt, J. L.; Ottiger, M.; Bax, A. J. Am. Chem. Soc 1998, 120 (27), 6836-6837.

(15) Pattenden, G.; Ashweek, N. J.; Baker Glenn, A. G.; Walker, G. M.; Lee J. G. K. Angew. Chem. Int. Ed. 2007, 46, 4359-4363.

JA075876L 